\title{
Retrospective studies and definition of endpoints
}

\author{
Habib A. Dakik, MD, FASNC ${ }^{a}$ \\ a Department of Internal Medicine, American University of Beirut Medical Center, Beirut, \\ Lebanon
}

Received Jul 21, 2020; accepted Jul 21, 2020

doi: $10.1007 / \mathrm{s} 12350-020-02329-4$

\section{See related article, pp. $101-110$}

End Stage Renal Disease (ESRD) is a challenging clinical endpoint for diabetes and hypertension as well as less common primary kidney disorders. These patients carry a particularly high risk for cardiovascular complications. Hence the role of non-invasive cardiac imaging in providing diagnostic as well as prognostic data in this group of patients is very essential and relevant. In this issue of the journal, Kolkailah et al report on the prognostic utility of Regadenoson SPECT myocardial perfusion imaging (MPI) in a large cohort of 1227 patients with ESRD. ${ }^{1}$ The group demonstrated a significant incremental prognostic value of Regadenoson MPI in predicting major adverse cardiac events (MACE) in these patients. The findings are consistent with previous smaller studies looking at Regadenoson as well as other pharmacologic stressors or exercise MPI in patients with ESRD. ${ }^{2-6}$ Given the large sample size, this report will serve as an important reference for future studies looking at the prognostic power of non-invasive cardiac imaging in ESRD patients. However, few limitations will need to be highlighted.

A very important limitation relates to definition of endpoints. The authors report an overall mortality of $16.6 \%$ with only $2.2 \%$ attributed to cardiac death. This is somewhat surprising, given that this is a relatively young cohort of patients with a mean age of 54 years. This raises the possibility that some of the cardiac deaths have been missed and labeled as non-cardiac death

Reprint requests: Habib A. Dakik, MD, FASNC, Department of Internal Medicine, American University of Beirut Medical Center, Beirut, Lebanon; hd01@aub.edu.lb

J Nucl Cardiol 2022;29:111-2.

$1071-3581 / \$ 34.00$

Copyright (C) 2020 American Society of Nuclear Cardiology. instead, which might explain the relatively low MACE event rates compared to previous studies that the authors commented on. Another limitation relates to adequate characterization of the study population. ESRD represents a wide spectrum of patients and it is important to know the causes of renal failure in these patients as well as the duration of the ESRD before the MPI was done. A third limitation relates to interfering interventions in prognostic studies. The authors indicate that $30 \%$ of patients underwent renal transplantation during the study which is known to alter outcomes in ESRD patients. The authors did try to correct for this by performing sensitivity analysis.

All of the limitations listed above can be attributed to the retrospective nature of the study. These studies on large cohort of patients are becoming important resources in providing data on the characteristics of diseases and their natural history. Can we make this data better, more accurate, and reliable? This might be feasible in large single center labs where clinical research is active and ongoing. It will be very helpful to take more time when clinical databases and registries are initiated and go into more detail into the clinical characteristics that need to be collected as well a much more refined definition of the endpoints to be measured. This will hopefully increase the efficiency of this type of clinical research and improve the reliability of the data derived from it.

\section{Disclosure}

Habib A. Dakik has no conflict of interest to disclose.

\section{References}

1. Kolkailah A, Iskander M, Iskandaer F, Patel P, Khan R, Doukky R. The Prognostic Utility of regadenoson SPECT Myocardial Perfusion 
Imaging in Patients with End-Stage Renal Disease: The Largest Cohort to Date. J Nucl Cardiol, in Press.

2. Vij A, Golzar Y, Doukky R. Regadenoson use in chronic kidney disease and end-stage renal disease: A focused review. J Nucl Cardiol 2018;25:137-49.

3. Doukky R, Rangel MO, Wassouf M, Dick R, Alqaid A, Morales Demori R. The safety and tolerability of regadenoson in patients with end-stage renal disease: the first prospective evaluation. J Nucl Cardiol 2013;20:205-13.

4. Hage FG, Ghimire G, Lester D, McKay J, Bleich S, El-Hajj S, et al. The prognostic value of regadenoson myocardial perfusion imaging. J Nucl Cardiol 2015;22:1214-21.
5. Doukky R, Fughhi I, Campagnoli T, Wassouf M, Ali A. The prognostic value of regadenoson SPECT myocardial perfusion imaging in patients with end-stage renal disease. J Nucl Cardiol 2017;24:112-8.

6. Hakeem A, Bhatti S, Dillie KS, Cook JR, Samad Z, Roth-Cline $\mathrm{MD}$, et al. Predictive value of myocardial perfusion single-photon emission computed tomography and the impact of renal function on cardiac death. Circulation 2008;118:2540-9.

Publisher's Note Springer Nature remains neutral with regard to jurisdictional claims in published maps and institutional affiliations. 